\title{
Career Guidance of Teenagers and their Sociocultural Development and Adaptation in Modern World of New Technologies
}

\author{
Tatyana V. Zuyeva ${ }^{1, \#, *}$ and Adel T. Nyssanov ${ }^{2, \#}$ \\ ${ }^{1}$ Branch of the Academy of Public Administration under the President of the Republic of Kazakhstan in the \\ Kostanay Region, Kostanay, Republic of Kazakhstan \\ ${ }^{2}$ Public Fund "Scientific-Educational Foundation "SYNERGY", Kostanay, Republic of Kazakhstan
}

\begin{abstract}
Objective: Compilation and partial testing of a career guidance program for students with special training in high school.

Background: A modern teenager is formed as a personality in the conditions of a constant increase of prestige of a profession and readiness of the labour market for the formation of subject-matter specialists. Each teenager chooses a profession based on their current market situation and their perception of it not only by technical capabilities but also by social, cultural, and value orientations. In this regard, early identification of professional preferences and the establishment of a system of work with schoolchildren, point-oriented to the choice of a profession, is relevant. The relevance of the work is determined by the fact that such a choice is made without the ability to determine success in a specific professional field in advance.
\end{abstract}

Method: The main content of the formation of teenagers' knowledge and skills for professional activities in the sociocultural environment were the disciplines of the variable part of the curriculum and the special course "Features of professional activity in the sociocultural environment". The methodology for creating and implementing a special course is focused on the formation of the basic components of readiness for professional activity in the sociocultural environment: personal, interactive, and reflective (evaluative).

Results: The article not only analyses the current experience of career guidance but also proposes to analyse the situation of teenagers' susceptibility to such guidance basing on different components. The practical significance of the study is determined by long-term projects, which are considered as a probabilistic improvement of socio-economic development and improvement of the quality of work in various industries, and at the personal level - sociocultural development and socialisation of teenagers.

Conclusion: The career guidance of teenagers should combine not only a story of a target audience about the benefits of a profession, but also about ways of communication and formation of a definition of technological way to bring information about the choice of profession.

Keywords: Higher education institutions, career guidance, sociocultural development, technology.

\section{INTRODUCTION}

Currently, there is a big problem in choosing a profession for students with mental retardation (intellectual disabilities). Due to the psychophysical features, it is challenging for students with mental retardation (intellectual disabilities) to navigate in the conditions of the modern labour market; therefore, this issue is relevant $[1,2]$.

Career guidance for schoolchildren is a process that begins in elementary school and is being conducted right up to graduation. It is built into the system of professional self-determination of a pupil. The purpose of professional self-determination is the gradual formation in pupils of internal readiness to

*Address correspondence to this author at the Branch of the Academy of Public Administration under the President of the Republic of Kazakhstan in Kostanay Region, Kostanay, Republic of Kazakhstan; Tel: ++77142575124 ; E-mail: t.zuyeva4828@nuos.pro

"These authors are equally contributed. independently, consciously plan, adjust and outline the prospects for their development (social, professional, and personal), which is one of the key aspects of their sociocultural development. Simultaneously, sociocultural development is a process of qualitative change in an individual as a subject of culture and social relations aimed at the development of cultural values, personal and socially significant levels. The goal of the vocational guidance system for schoolchildren is to develop a conscious and positive attitude to work activity among the young generation. In this process, a teacher is given the role of an assistant who introduces various areas of professional activity to pupils and contributes to the conscious choice of the profile of education [3].

The career guidance of children of high school age with mental retardation is an extremely urgent issue and requires careful study. The lack of a unified system of qualified career guidance assistance, insufficient development of career guidance methods, and targeted 
employment of persons with mental retardation leads to the lack of demand for this category of citizens and dramatically reduces their social protection. The objects of study in the process of career guidance in case of violations in intellectual development are professionally significant personality characteristics: professional interests, professional orientation, inclinations, and abilities, including intellectual development features; value orientations and meanings of activity, both educational and professional, health, including such personal characteristics as temperament and personality [4-7].

Career guidance needs to be carried out without interruption from the moment a child enters school, and a class teacher occupies the main position. Firstly, a class teacher's task is to provide pupils with up-to-date information about modern specialities and outline the requirements for different areas of professional activity. It is important to do this in an accessible and understandable way. For this, various techniques for career guidance are used. Secondly, the teacher's duty is to stimulate the interest of schoolchildren in various types of both classroom and extracurricular activities. Encouraging students to actively try their hand and strive for work will help to form a predisposition to certain areas of work and will facilitate the choice of the profile of education and profession in the future [8].

Finally, it is the task of a class teacher to conduct a guidance test for pupils. Questioning and testing help to study the personal qualities of pupils. Pupils fill out forms with assignments, on the basis of which teachers draw up their psychological and pedagogical characteristics, and also consult with their parents. It is important to understand that career guidance begins with elementary grades and is continuously conducted until graduation. At each age stage, there are their own tasks that teachers should take into account when career guidance for schoolchildren. The principles of work with different age groups of students are universal [9].

A part of students with mental retardation (intellectual impairment) of special (correctional) educational schools go to production, performing heavy unskilled low-paid types of labour there, but the majority of students with mental retardation (intellectual impairment) continue their education in educational institutions, mainly special groups of vocational training schools. In the future, students experience difficulties in finding employment, which is caused by several factors: psychological unreadiness at the time of transition from training to the sphere of professional labour; lack of clear, specific life prospects, the main reason is the lack of a sense of social security; inadequate self-esteem of abilities and capabilities upon choosing a profession; the inability to adequately assess the impact of the industrial microclimate on the student and the lack of readiness to overcome certain professional difficulties. Thus, several serious unsolved issues hinder the professional integration of students with mental retardation (intellectual disabilities) into society. Career guidance should be aimed at mainstreaming students' professional selfdetermination with mental retardation (intellectual disabilities) [10,11].

The purpose of the study lies in the compilation and partial testing of a career guidance program for students with mild mental retardation (intellectual disabilities) in high school.

\section{MATERIALS AND METHODS}

The main content of the formation of knowledge and skills of teenagers with mild mental retardation (intellectual disability) for professional activities in the sociocultural environment were the disciplines of the variable part of the curriculum and the special course "Features of professional activity in the sociocultural environment". The methodology for creating and implementing a special course is focused on the formation of the basic components of readiness for professional activity in the sociocultural environment: personal, interactive, and reflective (evaluative).

The study was conducted by the method of questioning among pupils in grades 5-11 during July 2019 in schools No. 5, No. 22 and No. 115 of the city of Kostanay in the Republic of Kazakhstan. The survey involved 1.400 children - 200 people from each age group.

In order to verify the acquired material, it was proposed to answer the questions: "What types of feelings are distinguished depending on their orientation?", "Describe the inducing function of the will", "Give definitions of character", "Describe the basic concepts and keywords: extraversion, introversion, extroverts, introverts, ambiverts, emotional stability (instability), temperament, choleric, sanguine, phlegmatic, melancholic, strength, poise, mobility", "What is the difference between abilities and inclinations?", "Give a typology of character accentuations", etc. 
To diagnose the skills of teenagers with mild mental retardation (intellectual disability) during the formative experiment, the case-study method was also used, since it makes it possible to bring the learning process closer to real practical activity. The main goal of the case-study method is to teach group analysis of the problem and independent decision making using the example of a specific situation (case). We used the methods of group training and decision making, contributing to the effective analysis of situations that arise in the shortest possible time, teach teenagers with mild mental retardation (intellectual disability) to work in one team, to defend their point of view, taking into account the opinions and criticisms of others. Thanks to this, the spirit of competition develops, activity, and leadership abilities in the group are manifested.

In addition, work was constantly carried out to ensure pedagogical conditions for the effective formation of teenagers' with mild mental retardation (intellectual disability) readiness for professional activities in the sociocultural environment: the orientation of the activities of the unscientific pedagogical worker towards the formation of adolescents' readiness for professional activities in the sociocultural environment; the desire to realise a personality-oriented content of training for teenagers; the presence of a reflective attitude of adolescents to their own preparation in the process of vocational training; the use of non-simulation and simulation methods that activate the educational and cognitive activities of adolescents with mild mental retardation (intellectual disability).

Forms of career guidance for students with mild mental retardation (intellectual disability), in our opinion, are no different from forms of work with other children and adolescents. When planning work in one form or another, the teacher must consider the students' physiological and psychological features and dose the time and load, if necessary, use additional technical or other means. Forms of career guidance with children and adolescents with developmental disabilities are quite diverse: professionally-oriented conversations; classes in clubs, workshops; careeroriented role-playing games, quests; excursions to enterprises, to vocational training and higher education institutions, to the employment service; meetings with specialists; participation in "open door days" held by universities and colleges; professional tests and social practices; participation in career guidance competitions, exhibitions, festivals; use of information stands, wall newspapers, sites, etc. [12].

\section{RESULTS}

After the formative stage of the experiment, we remeasured the parameters of teenagers' readiness for professional activity in the sociocultural environment in the process of vocational training to determine the effectiveness of the proposed technology. The presence of quantitative changes was determined by comparing the data of a state and control study in the experimental and control groups. After the reexamination of the motivational constituent of the personality component of readiness of teenagers with mild mental retardation (intellectual disability) for professional activities in the sociocultural environment, our results are grouped by ranking. More clearly, the differences in the results of ascertaining and control diagnostic studies by the level of the motivational constituent of the personality component of teenagers' readiness for professional activity in the sociocultural environment are presented using the diagram (Figure 1).

The peculiarity of the methodology used by us to diagnose the socio-psychological attitudes of a personality in the motivational-need sphere is the lack of juxtaposition of the proposed scales "process-result" and "altruism-egoism". That is, an increase in indicators for one indicator does not lead to a mechanical drop in another way, since all of them are significant for the future professional activity of a teenager. Changes in the results of teenagers with mild mental retardation (intellectual disability) in the control and experimental groups are shown in Figure 1.

Figure 1 demonstrates that the indicators of the motivational constitute of the personality component of the readiness of teenagers with mild mental retardation (intellectual disability) in the experimental group grew as much as possible on the "altruism" scales and "result. The indicators of the "process" scale practically did not change. At the same time, there is a drop in the results of the experimental group on the "egoism". In the control group of teenagers with mild mental retardation (intellectual disability), the studied parameters at the productive level also changed, but less significantly.

After the formative stage of the experiment, a reevaluation of the state of formedness of the sphere of value orientations of the personal component of 


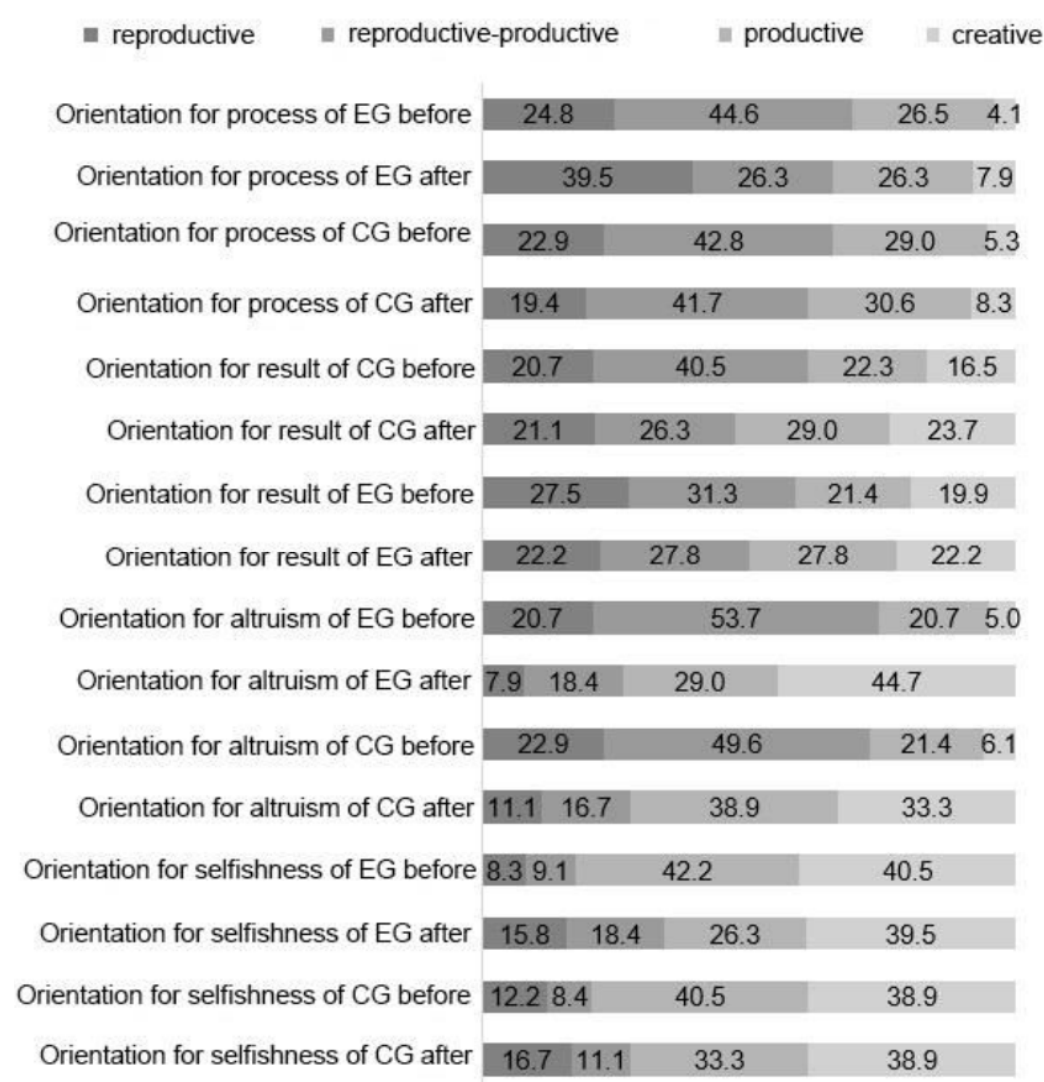

Figure 1: The Level of Formedness of the Motivational Constituent of the Personality Component of Readiness of Teenagers with Mild Mental Retardation (Intellectual Disability) for Professional Activity in the Sociocultural Environment (before and after the Formative Stage of the Experiment.

adolescents' readiness for professional activity in the sociocultural environment was carried out, which made it possible to identify the dynamics of its levels. The dynamic of the formedness of terminal values of teenagers with mild mental retardation (intellectual disability) is shown in Figure 2.

During the formative phase of the experiment, attention was paid to the formation of professional values of adolescents with mild mental retardation (intellectual disability). The results of the control diagnostic study also indicate positive changes in teenagers with mild mental retardation (intellectual disability) in the experimental group in terms of the formation of terminal values of teenagers compared with teenagers in the control group. The results are shown in the diagram (Figure 2).

In the experimental group, the number of teenagers with mild mental retardation (intellectual disability) with creative and productive levels of formedness of the values of professional self-realisation significantly increased. In the control group, such an increase is not observed. The results of the ranking of values are indicative, in which teenagers with mild mental retardation (intellectual disability) of the EG most often put in the first positions the values of professional selfrealisation. Respondents put "specific" and "abstract" values in the middle positions of their value-orientation scale. Other values, according to the arithmetic mean results, can be put in low positions in the hierarchy of values.

So, thanks to the pedagogical impact, such values as: active lifestyle and self-confidence occupy middle positions. Thus, in the experimental group, there is a positive dynamic in the level of formedness of the terminal values of adolescents. In the control group, such dynamics are less significant. This indicates that the level of values of professional self-realisation in the experimental group is higher than in the control group, which allows to recognise the effectiveness of the technology of the formation of readiness of teenagers with mild mental retardation (intellectual disability) for professional activities in the sociocultural environment. The dynamics of the formedness of the instrumental values of teenagers are shown in Figure 3 . There is a similar trend regarding the instrumental values of teenagers with mild mental retardation (intellectual 


$$
\begin{aligned}
& \text { = active lifestyle } \\
& =\text { interesting job } \\
& =\text { = financial well-being } \\
& =\text { cognition } \\
& =\text { amusement } \\
& =\text { hapiness of others }
\end{aligned}
$$

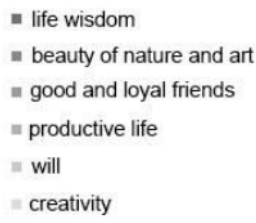

nealth

= love

= public recognition

= development

" happy family life self-confidence

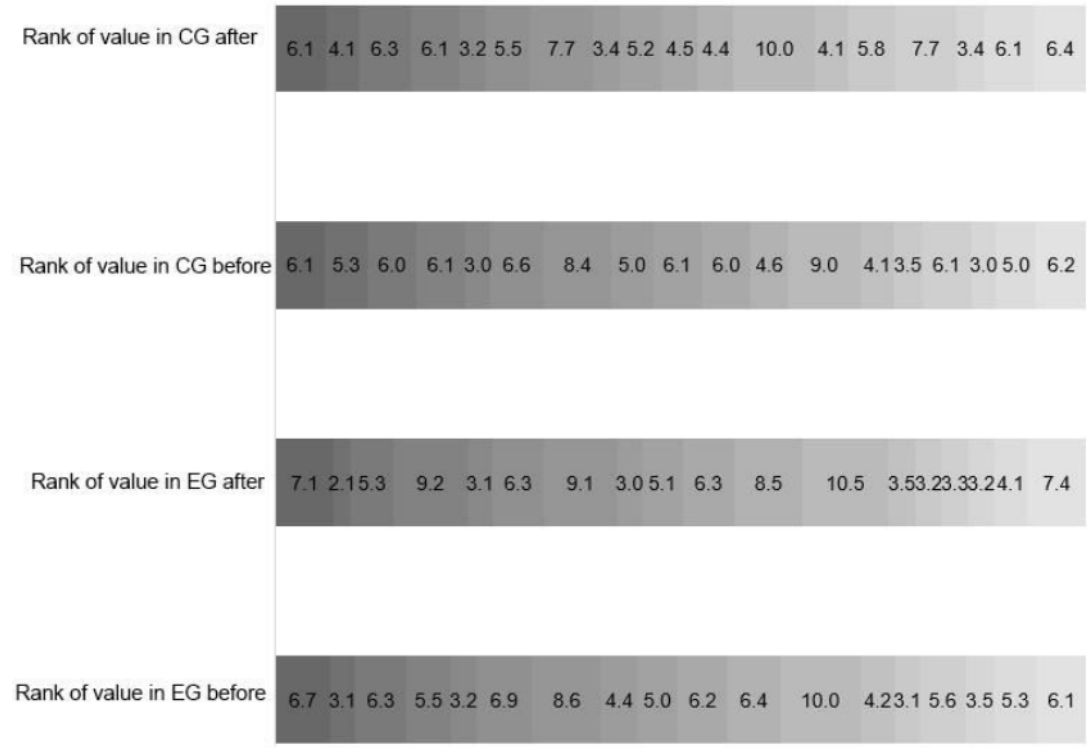

Figure 2: Dynamics of Formedness of Terminal Values of Teenagers with Mild Mental Retardation (Intellectual Disability) before and after the Formative Stage of the Experiment.

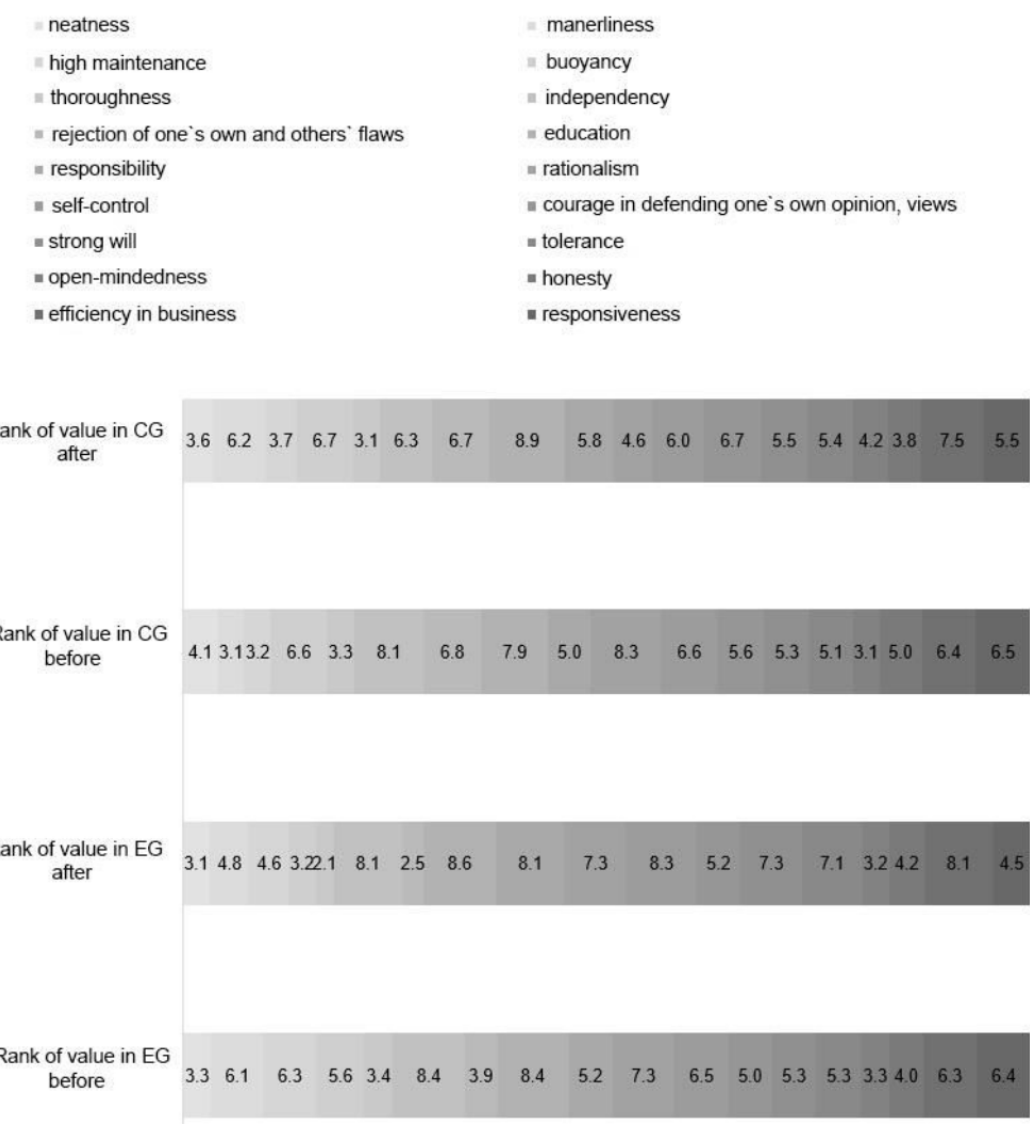

Figure 3: Dynamics of Formedness of Instrumental Values of Teenagers with Mild Mental Retardation (Intellectual Disability) before and after the Formative Stage of the Experiment. 
disability). In the control group, almost no changes occurred (Figure 3).

Only "education" has grown from 7.9 to 8.9 due to training. Teenagers with mild mental retardation (intellectual disability) of the experimental group considered the most important values of the business, the values of self-affirmation, and the value of communication. So, with the help of educational and methodological influence on the respondents, an increase in the importance of such values as responsibility, self-control, strong will, tolerance, and efficiency in business is observed for them. The values of professional self-realisation, as well as the values of the business, are quite significant value orientations for teenagers with mild mental retardation (intellectual disability) and correspond to creative and productive levels.

Medium significant are the following ethical and individualistic values: courage in defending one's own opinion, views - 5.2; mannerliness (good manners) 4.8; high maintenance on their own lives -4.6 . The remaining conformist, altruistic, and individualistic instrumental values are less significant for the respondents. This allows concluding that the technology proposed by us is effective. It is needed to consider the results of teenagers with mild mental retardation (intellectual disability) after the formative stage of the experiment on the emotional constitution of the personality component of the readiness of teenagers with mild mental retardation (intellectual disability) for professional activities in the sociocultural environment. For clarity, the results of the emotional constitute of the personality criterion were shown in Figure 4.

During the ascertaining stage of the experiment, we identified sufficient obstacles in establishing emotional contacts in teenagers with mild mental retardation (intellectual disability). However, after the formative stage of the experiment, the inability to control emotions in teenagers of the experimental group as an obstacle to future professional activity in the sociocultural environment decreased from $66.1 \%$ to $39.5 \%$; inadequate display of emotions - from $60.0 \%$ to $31.6 \%$; the inflexibility of emotions fell from $18.2 \%$ to $15.8 \%$; the dominance of negative emotions - from $15.7 \%$ to $10.5 \%$; unwillingness to let people in on an emotional basis - from $12.4 \%$ to $7.9 \%$. The

\footnotetext{
- Inability to control emotions, to measure out them

- Inadequate display of emotions

- Inflexibility, underdevelopment, slurredness of emotions

$=$ Dominance of negative emotions

Unwillingness to let people in on an emotional basis
}

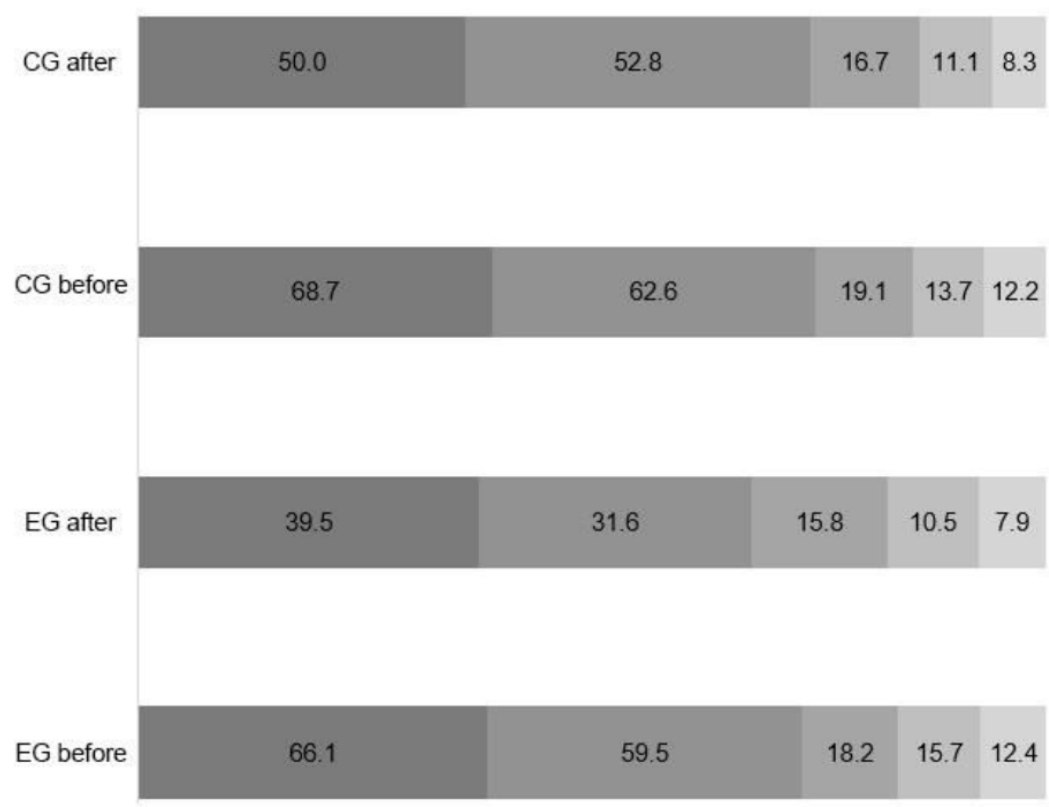

Figure 4: The Results of the Study of "Interferences" in the Establishment of Emotional Contacts in Teenagers with Mild Mental Retardation (Intellectual Disability) before and after the Formative Stage of the Experiment. 
characteristic of obstacles in the identification of emotions makes it possible to determine the general level of conscious control over emotions and the ability to use them in the professional activities of teenagers with mild mental retardation (intellectual disability) in a sociocultural environment.

As can be seen from Figure 4 , the greatest improvement trends in the experimental group after the formative stage of the experiment are observed on the scales "inability to control emotions" and "inadequate display of emotions". Moreover, the results of the control group remained almost unchanged. We explain such changes by the effectiveness of the technology proposed for working with teenagers with mild mental retardation (intellectual disability). The obtained general indicators of the emotional constitute of the personality component of readiness of teenagers with mild mental retardation (intellectual disability) for professional activities in sociocultural activities are more clearly presented as the differences between the results of ascertaining and formative studies of the level of formedness of the emotional constitute of the personal component of readiness of teenagers with mild mental retardation (intellectual disability) for professional activities in the sociocultural environment using the graph (Figure 5).
It can be stated that in the control group, after the formative stage of the experiment, there is an increase in the number of teenagers with mild mental retardation (intellectual disability) with a productive level of the emotional constitute of the personal component of the readiness of teenagers with mild mental retardation (intellectual disability) for professional activity in the sociocultural environment (from $11.5 \%$ to $36.1 \%$ ), which can be explained by the peculiarity of their professional training, including teaching a cycle of disciplines of independent choice. At the same time, after the formative stage of the experiment, representatives of the experimental group more than doubled the productive level of the emotional constitute of the personal readiness component. Emotions do not interfere with professional communication in $18.4 \%$ of teenagers of the experimental group and $16.67 \%$ of the control groups, which corresponds to the creative level of formedness of the emotional constitute of the personal readiness component. At the same time, the share of teenagers with mild mental retardation (intellectual disability) with reproductive (from $25.6 \%$ to $10.5 \%$ ) and reproductive-productive (from $49.6 \%$ to $31.6 \%)$ levels are falling. So, despite the fact that the respondents have some emotional problems in everyday communication, they are generally consistent with the norm, because these problems are inherent in

m Creative (high) $-1-5$ points

= Productive (above average) $-6-8$ points

$=$ Reproductive-productive (below average) - 9-12 points

- Reproductive (low) - 13 points and more

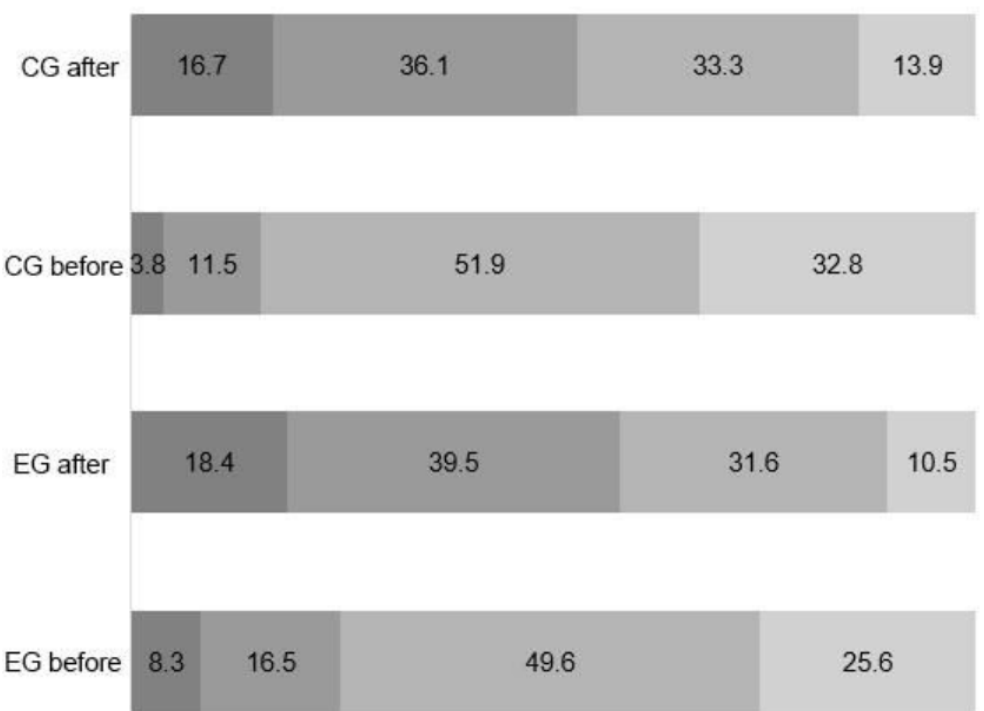

Figure 5: The Level of Formedness of the Emotive Constitute of the Personality Component of the Readiness of Teenagers with Mild Mental Retardation (Intellectual Disability) for Professional Activities in the Sociocultural Environment (before and after the Forming Stage of the Experiment). 
any person. This confirms the effectiveness of our proposed technology for the formation of adolescent preparedness for professional activities in the sociocultural environment.

We separately studied the communicative and organisational skills of teenagers with mild mental retardation (intellectual disability) before and after the formative stage of the experiment as indicators of the interactive component of readiness for professional activity in the sociocultural environment. The main indicator of the interactive component of readiness is the communicative skills that a specialist needs since communication is extremely important for achieving a positive result in professional work in a sociocultural environment. Communicative skills are the basis of professional activity, as they ensure performing all professional functions; communicative interaction is a component of all areas of work in the sociocultural environment. The dynamics of changes in the level of development of communicative skills of teenagers with mild mental retardation (intellectual disability) in the control and experimental groups before and after the formative stage of the experiment is presented in Figure 6.

The level of development of communicative skills as an interactive component of readiness of teenagers with mild mental retardation (intellectual disability) for professional activity in the sociocultural environment has changed both in the control and experimental groups. So, in the experimental group, the redistribution of adolescents with different levels of development of communicative skills is greater than in the control group: the creative level has changed from $8.3 \%$ to $18.4 \%$; productive - from $9.1 \%$ to $36.8 \%$; reproductive-productive - from $42.2 \%$ to $31.6 \%$; reproductive - from $40.5 \%$ to $13.2 \%$. In the control group, the number of studied teenagers with mild mental retardation (intellectual disability) with a creative level of development of communicative skills changed from $8.4 \%$ to $16.7 \%$; with productive - from $9.9 \%$ to $36.11 \%$; with a reproductive-productive level - from $41.2 \%$ to $33.3 \%$; with reproductive - from $40.5 \%$ to $13.9 \%$. Changes in the levels of development of communicative skills in both groups can be explained by professional training, in particular, the cycle of disciplines of independent choice. However, changes in the indicators of the experimental group compared with the control can only be explained by the influence of the implementation of the technology for the formation of readiness of teenagers with mild mental retardation (intellectual disability) for professional activity in the sociocultural environment in the process of professional training.

- Creative (high) -13 points and more

= Productive (above average) - 9-12 points

= Reproductive-productive (below average) $-5-8$ points

= Reproductive (low) -4 point and below

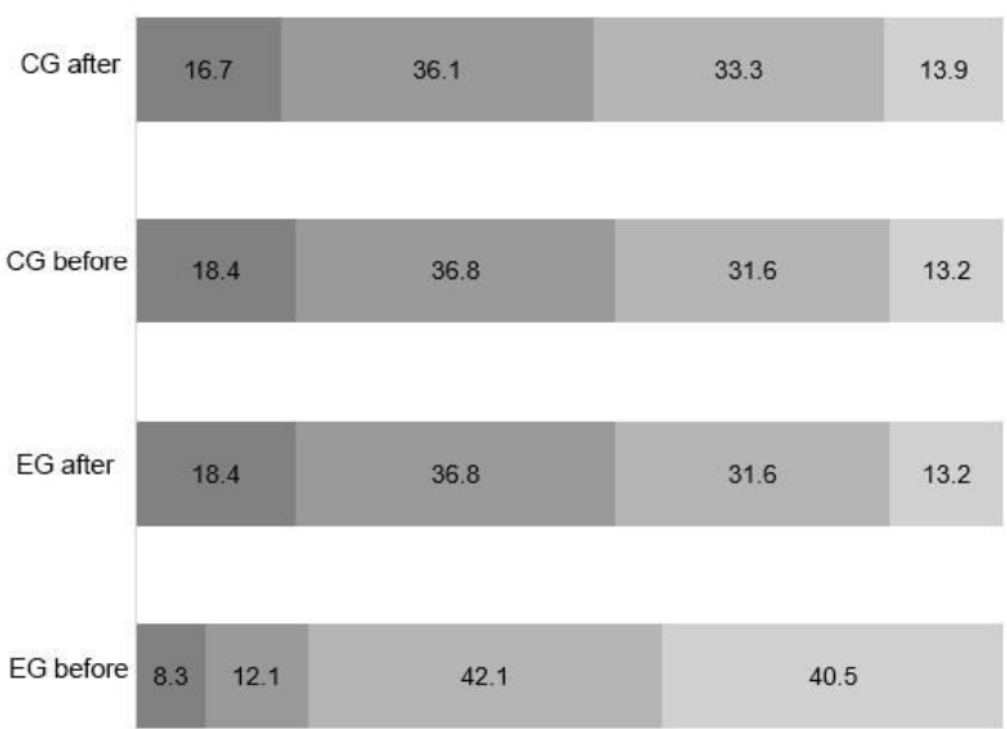

Figure 6: The Results of the Study of Formedness of the Interactive Component of Readiness of Teenagers with Mild Mental Retardation (Intellectual Disability) for Professional Activities in the Sociocultural Environment before and after the Formative Stage of the Experiment on the Scale "Communicative Skills". 
= Creative (high) -13 points and more

$=$ Productive (above average) $-9-12$ points

$=$ Reproductive-productive (below average) $-5-8$ points

$=$ Reproductive (low) -4 points and low

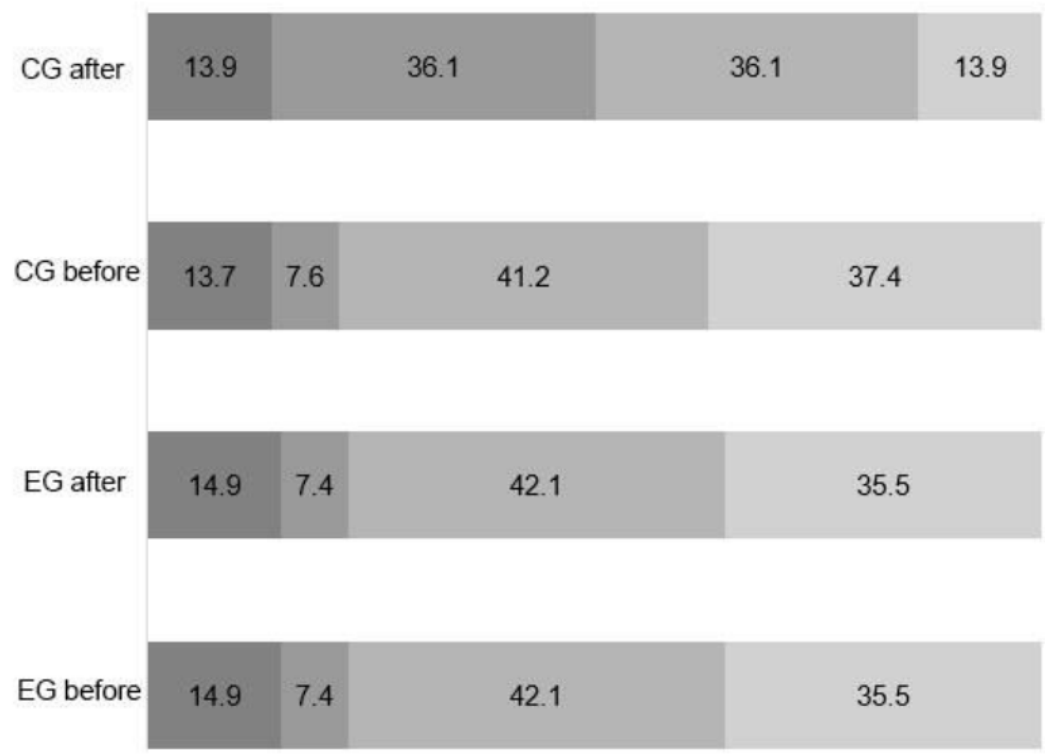

Figure 7: The Results of the Study of Formedness of the Interactive Component of Readiness of Teenagers with Mild Mental Retardation (Intellectual Disability) for Professional Activities in the Sociocultural Environment before and after the Forming Stage of the Experiment on the Scale "Organisational Skills".

Also, the organisational skills of teenagers in the control and experimental groups after the formative stage of the experiment were studied, which also underlie the readiness of teenagers with mild mental retardation (intellectual disability) for professional activities in the sociocultural environment, since the presence of a high level of formation of organisational skills will help a psychologist in creating psychological contact with specialists. The dynamic of changes in the level of development of organisational skills of teenagers with mild mental retardation (intellectual disability) is shown in Figure 7.

The data obtained indicate that in the experimental group, the productive level of development of organisational skills increased more than in the control group from $7.4 \%$ to $39.5 \%$. We associate the increase in the productive level of development of organisational skills in the CG with the teaching of disciplines of independent choice. The creative level in the EG increased from $14.9 \%$ to $15.8 \%$. In $E G$, the reproductive and productive level of development of communicative skills decreased from $42.1 \%$ to $31.6 \%$. The reproductive level in teenagers of the EG decreased from $35.5 \%$ to $13.7 \%$, and in the CG from $37.4 \%$ to $13.89 \%$. Such changes can be considered evidence of the effectiveness of the proposed technology.

To diagnose the skills of teenagers with mild mental retardation (intellectual disability) during the formative experiment. All cases encouraged teenagers to develop practical skills and also developed practical skills. They helped the pupils to feel more confident in the release of their practical knowledge and skills in further activities, which would significantly reduce the adaptation of these teenagers in a professional environment. We obtained significantly better results in teenagers with mild mental retardation (intellectual disability) of the EG than in the CG. Since the respondents of the EG showed a creative (high) level of professional skills, it can be argued that this was achieved with the help of pedagogical influence - the implementation of the technology of formation of readiness of teenagers with mild mental retardation (intellectual disability) for professional activity in the sociocultural environment in the process of training and the influence of specially created pedagogical conditions. Reflection was also studied as an indicator of the estimated component of readiness of teenagers with mild mental retardation (intellectual disability) for professional activities in the sociocultural environment 
- Creative (high)

- Productive (above average)

= Reproductive-productive (below average)

$=$ Reproductive (low)

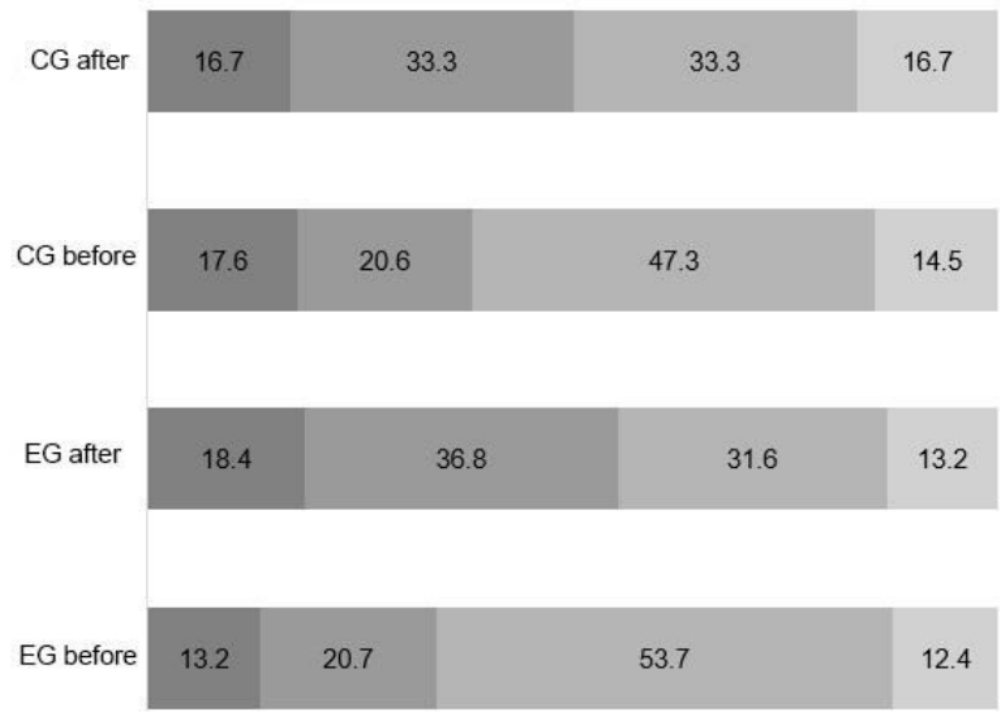

Figure 8: Levels of Formedness of the Reflective Component of Teenagers with Mild Mental Retardation (Intellectual Disability) Readiness for Professional Activities in the Sociocultural Environment before and after the Formative Stage of the Experiment.

before and after the formative stage of the experiment. The change in the level of reflection of teenagers with mild mental retardation (intellectual disability) is shown in Figure 8.
The self-assessment results of teenagers with mild mental retardation (intellectual disability) are confirmed by the methodology for the determination of the reflection level. We obtained the following results

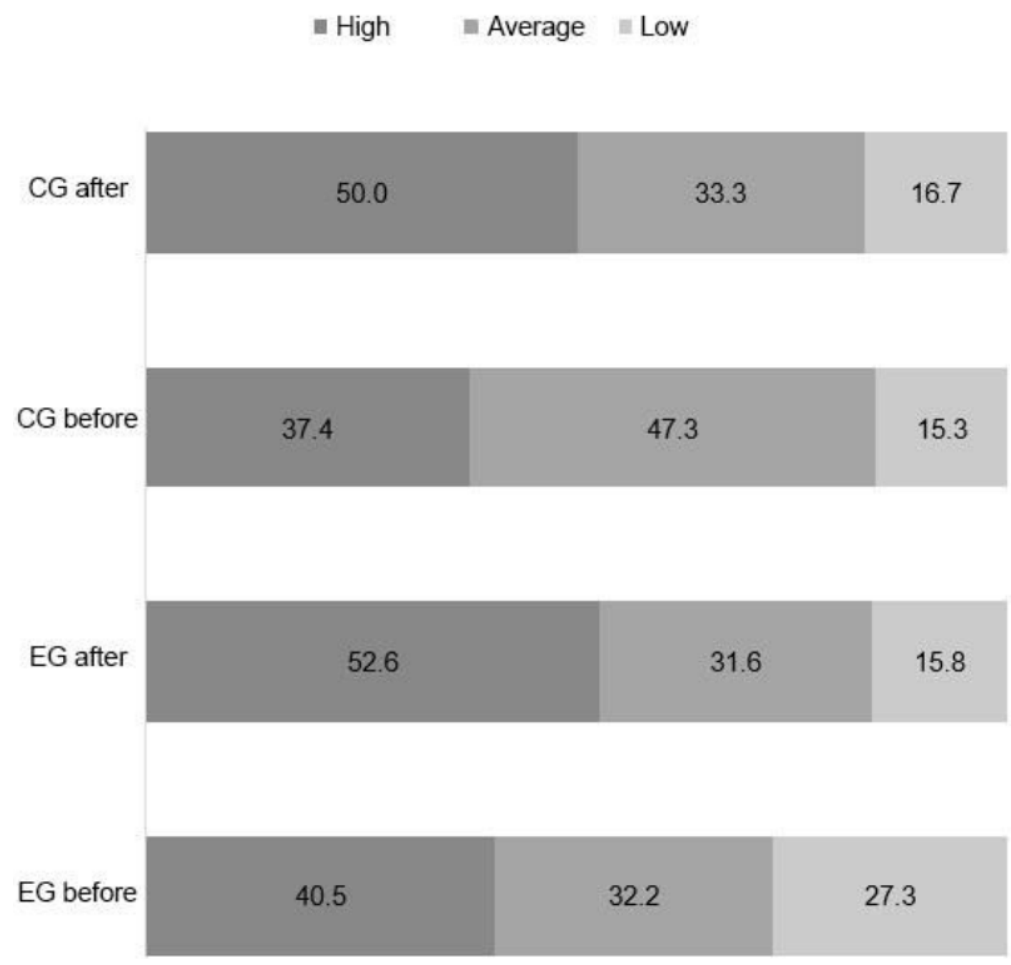

Figure 9: The Level of Formedness of the Reflection of Teenagers with Mild Mental Retardation (Intellectual Disability) by the Method of Determination of Reflection Level. 
(Figure 9): a high level of reflectivity increased from $40.5 \%$ to $52.6 \%$ in the $E G$ and from $37.4 \%$ to $50.0 \%$ in the CG. Since the high level of development of reflection positively affects the provision of psychological activity in the sociocultural environment, it can be argued about the effectiveness of the technology developed in the research process and the creation of appropriate pedagogical conditions.

\section{DISCUSSION}

All data obtained during the diagnostic process were summarised in the level of teenagers with mild mental retardation (intellectual disability) readiness for professional activities in the sociocultural environment, the dynamic of which is reflected in Table 1. The motivational constitute of the personality component is presented on the scale "Orientation for result", because it reflects the desire of a future specialist to achieve results in his professional activity, and the interactive component is presented on the scale "Communicative skills", because the ability to communicate is one of the most important qualities of a psychologist, necessary for his work.

According to the data in Table 1, at the ascertaining stage of the experiment, the levels of formedness of readiness of teenagers with mild mental retardation (intellectual disability) for professional activity in the sociocultural environment among teenagers in the CG and $E G$ were relatively identical. After the completion of the formative stage of the experiment, during which the technology of formation of readiness of teenagers with mild mental retardation (intellectual disability) for professional activity in the sociocultural environment was introduced, it was determined that in the EG the creative (high) and productive (above average) level of readiness of teenagers with mild mental retardation (intellectual disability) for professional activity in the sociocultural environment. In the CG, the creative (high) and productive (above average) level of readiness of teenagers with mild mental retardation (intellectual disability) for professional activity in the sociocultural environment grew primarily due to an increase in the general readiness and positive dynamics of the emotional constitute of the personal component $(16.7 \%$ and $36.1 \%)$ and reflective (evaluative) components ( $16.7 \%$ and $33.3 \%)$.

However, in the experimental group, the proportion of teenagers with mild mental retardation (intellectual disability) with reproductive and reproductiveproductive levels of readiness for professional activity in the sociocultural environment remained. This fact is explained by the presence of people who are not ready to carry out psychological activities due to unwillingness to work, to take responsibility for the mistakes of specialists, the lack of practical preparation for professional activity, the random choice of the profession of a psychologist, the desire to get a higher education and other objective factors [13]. In this

Table 1: Levels of Formedness of Readiness for Professional Activity before and after the Experiment

\begin{tabular}{|c|c|c|c|c|c|c|c|c|c|}
\hline \multirow{2}{*}{\multicolumn{2}{|c|}{ Components }} & \multicolumn{2}{|c|}{ Creative } & \multicolumn{2}{|c|}{ Productive } & \multicolumn{2}{|c|}{ Reproductive-productive } & \multicolumn{2}{|c|}{ Reproductive } \\
\hline & & 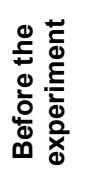 & 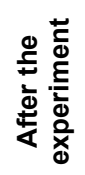 & 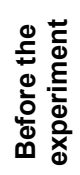 & 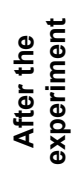 & 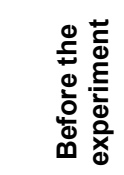 & 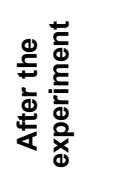 & 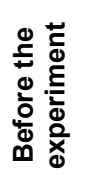 & 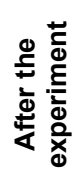 \\
\hline \multirow{2}{*}{$\begin{array}{l}\text { The } \\
\text { motivational } \\
\text { constituent of } \\
\text { the personality } \\
\text { component }\end{array}$} & EG & 16.5 & 23.7 & 22.3 & 29.0 & 40.5 & 26.3 & 20.7 & 21.1 \\
\hline & CG & 19.9 & 22.2 & 21.4 & 27.8 & 31.3 & 27.8 & 27.5 & 22.2 \\
\hline \multirow{2}{*}{$\begin{array}{l}\text { The emotional } \\
\text { constituent of } \\
\text { the personality } \\
\text { component }\end{array}$} & EG & 8.3 & 18.4 & 16.5 & 39.5 & 49.6 & 31.6 & 25.6 & 10.5 \\
\hline & CG & 3.8 & 16.7 & 11.5 & 36.1 & 51.9 & 33.3 & 32.8 & 13.9 \\
\hline \multirow{2}{*}{$\begin{array}{l}\text { The interactive } \\
\text { component }\end{array}$} & EG & 8.3 & 18.4 & 9.1 & 36.8 & 42.2 & 31.6 & 40.5 & 13.2 \\
\hline & CG & 8.4 & 16.7 & 9.9 & 36.1 & 41.2 & 33.3 & 40.5 & 13.9 \\
\hline \multirow{2}{*}{$\begin{array}{l}\text { The reflective } \\
\text { (evaluative) } \\
\text { component }\end{array}$} & $E G$ & 13.2 & 18.4 & 20.7 & 36.8 & 53.7 & 31.6 & 12.4 & 13.2 \\
\hline & CG & 17.6 & 16.7 & 20.6 & 33.3 & 47.3 & 33.3 & 14.5 & 16.7 \\
\hline
\end{tabular}


regard, it can be noted that the number of teenagers with mild mental retardation (intellectual disability) of productive (above average) and creative (high) levels of preparedness in the experimental group increased, while the number of teenagers with mild mental retardation (intellectual disability) of reproductive (low) level decreased after the special course.

Research by M.S. Pevzner and V.I. Lubovsky suggests that students with mild mental retardation (intellectual disability) most successfully master general practical and labour skills at the 7th-8th years of study. During this period, they need to discuss future issues. As a rule, representatives of the chosen profession have a practical orientation, which is connected with the nature of labour training at school and with already acquired labour skills and abilities. However, at the same time, mentally disabled students clearly prefer such specialities inaccessible to them as drivers, hairdressers, etc. [14, 15]. Gradually, they begin to give preference to the production professions available to them (seamstress, carpenter, locksmith, bookbinder, etc.). It reveals an overestimated self-esteem, which tends to objectify as the student grows older. Many students with mild mental retardation (intellectual disability) of senior classes are characterised by confidence and focus in specific practical activity accessible to them. High school students with mild mental retardation (intellectual disability) adequately experience their successes and failures persist in achieving a specific goal [16].

According to K.M. Turchinsky, the level of professional stability of graduates of special (correctional) schools is much lower than the level of professional stability of graduates of vocational training schools. Along with the frequent change of profession, there is a frequent change of place of work [17-19]. There are frequent cases when a graduate with mental retardation changes their job every year. Research by K.M. Turchinsky reveals the features of the manifestation of the professional interests of mentally disabled students in different periods of their education.

According to N. B. Migulina, career guidance work with mentally disabled students includes the following aspects: the formation of ideas about professions, the prospects for professional growth and skill, the rules for choosing a profession, the ability to adequately assess their personal capabilities in accordance with the requirements of the chosen profession, the formation of students' ability to the professional adaptation to modern socio-economic conditions, a conscientious attitude to work, the development of interest in work [20]. All this contributes to the improvement of the process of professional and social self-determination of students with mental retardation. Thus, the career guidance of students with mental retardation (intellectual disabilities) should be continuous in view of continuity with labour training in a special (correctional) school and vocational training school, be open and oriented at the same time to the needs of the labour market and the individual needs of the student. It is only the initial stage in the system of measures for the social and labour adaptation of persons with mental retardation, which depends on the success of their integration in society [21].

Guided by our results, we concluded that the professional orientation of adolescents with mild mental retardation (intellectual disability) should be carried out comprehensively, involving parents and various specialists in this process; methodological tools for determining the characteristics of students choosing a profession should be adapted to the capabilities of a teenager with mild mental retardation (intellectual disability); it is important to adjust the professional plans of each child in accordance with its abilities throughout the entire period of career guidance; based on the adjustment of professional plans, it is advisable to carry out psychological and pedagogical work to educate the qualities necessary for mastering a particular profession.

\section{CONCLUSIONS}

Career guidance constitutes a set of psychological and pedagogical measures that are aimed at the formation of professional interests and inclinations in students with mental retardation (intellectual disabilities) in accordance with their personal abilities and capabilities and is the main part of the educational work of educational institutions. The process of psychological and pedagogical measures mainly carried out at school, involves a targeted impact aimed at studying students with mental retardation (intellectual disabilities), as well as on their comprehension of the conditions under which their work will be carried out.

To form the readiness of teenagers with mild mental retardation (intellectual disability) for professional activities in the sociocultural environment, it is necessary to use situations-incidents that are aimed at overcoming a listener's personal inertness and the 
formation of an adequate psychological response in difficult, stressful situations that occur in the sociocultural environment. Using a lecture-debate, it is necessary to discuss the problem from today's perspective, which will contribute to the formation of a positive emotional response among young people with mild mental retardation (intellectual disability) regarding work in the sociocultural environment. During the discussion, it is necessary to pay attention to sociability development - one of the main qualities necessary for professional work.

In order to encourage young people with mild mental retardation (intellectual disability) to help overcome psychological consequences of extreme situations that a modern worker is dealing with in a sociocultural environment, it is necessary to create success situations for the personal growth of teenagers from overcoming difficulties, as well as balancing their emotional state and increasing self-esteem; to use suggestive technologies as a means of psychological impact on specialists, a means of self-regulation of a personality with the help of training, relaxation techniques; to stimulate the creative activity of teenagers, to use game educational technologies in the educational process, in which teenagers in a playful way are involved in solving urgent problems of professional practice.

When organising and using non-simulation and simulation training methods in the formation of readiness of teenagers with mild mental retardation (intellectual disability) for professional activity in the sociocultural environment in the process of training, a teacher must take into account the formation of all components of this type of readiness: personal, interactive and reflective (evaluative).

\section{ACKNOWLEDGEMENT}

None.

\section{REFERENCES}

[1] Ebrahim GJ. The troubled teens. In: Child care in the tropics. London: Macmillan Education UK 1978. https://doi.org/10.1007/978-1-349-15957-4 13

[2] Chen CP, Chan J. Career guidance for learning-disabled youth. International Journal for Educational and Vocational Guidance 2014; 14(3): 275-91. https://doi.org/10.1007/s10775-014-9270-6

[3] Gysbers NC. Comprehensive school guidance programs in the United States: A career profile. International Journal for Educational and Vocational Guidance 2005; 5(2): 203-15. https://doi.org/10.1007/s10775-005-8800-7
[4] Patton W. Perceptions of training needs of career guidance personnel before and after a university program. Journal of Career Development 2000; 26(3): 175-90. https://doi.org/10.1023/A:1022939131493

[5] Draaisma A, Meijers F, Kuijpers M. Innovating towards career learning environments: Changes in teachers' role perception regarding career guidance. In JG Maree (Ed.) Handbook of innovative career counselling. Cham: Springer International Publishing 2019; p. 711-30. https://doi.org/10.1007/978-3-030-22799-9 39

[6] Multon KD, Lapan RT. Developing scales to evaluate career and personal guidance curricula in a high school setting Journal of Career Development 1995; 21(4): 293-305. https://doi.org/10.1007/BF02106153

[7] Gfroerer M. Career guidance on the cutting edge of competency-based assessment. Journal of Career Development 2000; 27(2): 119-31. https://doi.org/10.1023/A:1007800717780

[8] Bernes KB, Bardick AD, Orr DT. Career guidance and counselling efficacy studies: an international research agenda. International Journal for Educational and Vocational Guidance 2007; 7(2): 81-96. https://doi.org/10.1007/s10775-007-9114-8

[9] Jones CJ, Peskin H. Psychological health from the teens to the 80s: Multiple developmental trajectories. Journal of Adult Development 2009; 17(1): Article number 20. https://doi.org/10.1007/s10804-009-9075-x

[10] Kassotakis M. Career counselling and guidance in Greece. In: RG Sultana (Ed.). Career guidance and livelihood planning across the Mediterranean: Challenging transitions in South Europe and the MENA region. Rotterdam: Sense Publishers 2017; p. 303-22. https://doi.org/10.1007/978-94-6300-992-8 19

[11] Watanabe-Muraoka AM, Takeshi Senzaki T-A, Herr EL. Donald Super's Contribution to Career Guidance and Counselling in Japan. International Journal for Educational and Vocational Guidance 2001; 1(1): 99-106

https://doi.org/10.1023/A:1016924915340

[12] Taveira MDC. Career Education and Guidance Services in Portugal. In RG Sultana (Ed.). Career guidance and livelihood planning across the Mediterranean: Challenging transitions in South Europe and the MENA region. Rotterdam: Sense Publishers 2017; p. 401-16. https://doi.org/10.1007/978-94-6300-992-8_25

[13] Patton W, McMahon M. Career development learning in school systems. In Career development and systems theory: Connecting theory and practice. Rotterdam: Sense Publishers 2014; p. 323-44. https://doi.org/10.1007/978-94-6209-635-6_12

Rusk N, Larson RW, Raffaelli M, Walker K, Washington L, Gutierrez V, Perry SC. Positive youth development in organised programs: How teens learn to manage emotions. In C Proctor, PA Linley (Ed.). Research, applications, and interventions for children and adolescents: A positive psychology perspective. Dordrecht: Springer Netherlands 2013; p. 247-61.

https://doi.org/10.1007/978-94-007-6398-2 15

[15] Dedmond R, Hufziger L. Career education and caree guidance: Strategies for implementing career development. Journal of Career Development 1989; 15(4): 257-64. https://doi.org/10.1007/BF01321969

[16] Zueva TV, Litvak RA. The concept of school and family as subjects of a sociocultural environment that contribute to the socialisation of a child's personality. Graduate Student 2016; 3: 93-95.

[17] Tanaeva ZR, Smagliy TI, Zueva TV, Pavlicenco AA, Elizarova EI, Kanapina SG, Sapieva MS, Kyfik NY. The modern teens' sociocultural development diagnostics and interaction between family and school. Opcion 2018; 34(Special Issue 16): 132-40. 
[18] Watanabe AM. Influences of microelectronics on education and training programs and career guidance in Japan. International Journal for the Advancement of Counselling 1985; 8(2): 115-23.

https://doi.org/10.1007/BF00119285

[19] Rowe FA, Mauer KA. Career guidance, career assessment, and consultancy. Journal of Career Development 1991; 17(3): 223-33.

https://doi.org/10.1007/BF01322029
[20] Wehrly B. Cultural and social influences on career guidance: An overview. International Journal for the Advancement of Counselling 1982; 5(2): 131-40. https://doi.org/10.1007/BF00119094

[21] Yip K. Excellence in education for Singapore: The role of career guidance. International Journal for the Advancement of Counselling 1990; 13(3): 185-91. https://doi.org/10.1007/BF00118483

Received on 25-07-2020

DOI: https://doi.org/10.6000/2292-2598.2020.08.03.28

(C) 2020 Zuyeva and Nyssanov; Licensee Lifescience Global.

This is an open access article licensed under the terms of the Creative Commons Attribution Non-Commercial License (http://creativecommons.org/licenses/by-nc/3.0/) which permits unrestricted, non-commercial use, distribution and reproduction in any medium, provided the work is properly cited. 